\title{
Experimental Research of Journal Orbit for Water-Lubricated Bearing
}

\author{
Xiaoyan Ye, Jing Wang, Desheng Zhang, Lanqian Hu, and Xunan She \\ Research Center of Fluid Machinery Engineering and Technology, Jiangsu University, Zhenjiang, Jiangsu 212013, China \\ Correspondence should be addressed to Jing Wang; wj1989716@sina.cn
}

Received 17 January 2016; Accepted 27 March 2016

Academic Editor: Yuqiang Wu

Copyright ( 2016 Xiaoyan Ye et al. This is an open access article distributed under the Creative Commons Attribution License, which permits unrestricted use, distribution, and reproduction in any medium, provided the original work is properly cited.

\begin{abstract}
To study the transient dynamic characteristics of water-lubricated bearing-rotor system in seawater desalination high pressure pump, the water-lubricated bearing test device was designed and built based on the prototype of high pressure pump with 4-stage rotors. The test was conducted to study the journal orbit and circumferential pressure distribution of journal bearing. The result shows that, in startup stage, the journal whirled with little amplitude in low revolution speed, and as the revolution speed increased, the journal began to move irregularly. The hydrodynamic lubrication formed basically when close to the rated revolution speed, and there is stable whirling center and amplitude of the journal orbit. The circumferential pressure distribution of journal bearing changed severely and kept consistent with the change of journal orbit; when the revolution speed reached the rated speed, the pressure distribution is stable. We changed the radius clearance, the aspect ratio, and the rotating speed to analyze the influence on the bearing-rotor system at steady speed. In conclusion, the journal orbit and circumferential pressure of journal bearing are very stable when the clearance radius is $0.05 \mathrm{~mm}$, the aspect ratio is 1 , and the revolution speed is $3000 \mathrm{r} / \mathrm{min}$.
\end{abstract}

\section{Introduction}

The water-lubricated bearing in seawater desalination pump not only simplifies the structure but also reduces the friction and energy consummation caused by the mechanical drive, which is due to the small friction factor of elastic hydrodynamic lubrication, and especially avoids the contamination caused by the leakage. But compared with the oil film, the low dynamic viscosity forms the low carrying capacity and it is difficult to form the hydrodynamic lubrication in complex lubrication condition. Though there is some progress in the research of lubrication mechanism, the water-lubricated bearing is treated as the independent research object, and most are theoretical [1-9] and simulation analysis [10-15]; there are few researches for the water-lubricated bearing and rotor system.

In recent years, many scholars conduct the experimental research in journal bearing. Liu [16] designed the waterlubricated bearing test device which consisted of the housing seat, shaft, loading cylinder, and journal bearing and a set of mutually perpendicular displacement sensors was placed in the side of the tested bearing. Pressure and temperature sensors were arranged along the shaft circumference ninety degrees apart. Zhang and Wag [17] built a water-lubricated bearing seal test device which is compatible for two lubricating mediums.

To achieve a real time monitoring and control of the test device quickly and stably, a metering pump was applied to measure dynamic seal leakage and dynamic seal friction, and temperature, leakage, and pressure were monitored by computer system. Zhang and Yuan [18] tested the journal bearing in high-speed, light-load, and high pressure conditions and designed a relevant test device which used lowviscosity lubricating medium. Two eddy current displacement sensors that are mutually perpendicular were arranged at the front and rear of tested bearing; film thickness in vertical and horizontal directions was tested. The test device could measure the power consumption varied with speed, as well as the water-supply pressure varying with film thickness. Dimond and Rockwell [19] developed a bearing test device for water-lubricated and oil-lubricated bearing. The test rig was designed with light weight, load stability, and highspeed based on the structure of turbines. High-speed turbines usually adopt oil-lubricated bearing, but they can provide some reference for water-lubricated bearing. Ozsarac and 


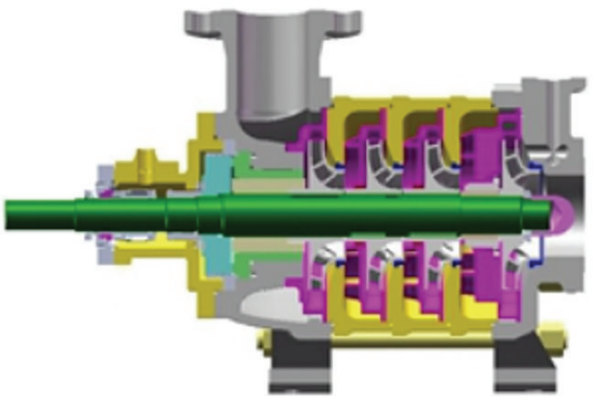

FIGURE 1: The structure of high pressure pump.

Findik [20] designed the journal bearing test device to study the friction and wear properties of oil-lubricated bearing. The friction and wear test were done on the condition of linear speed $0.5 \mathrm{~m} / \mathrm{s}$ and the test force of $10 \mathrm{~N}, 20 \mathrm{~N}$, and $40 \mathrm{~N}$. Wear loss could be obtained through the above experiment and the coefficients of friction were calculated. Wear and friction characteristics of journal bearing materials were discussed and analyzed by electron microscope observation of the surface wear.

Based on the above experimental research in journal bearing, we find few researches into the influence of the journal parameter and bearing-rotor system. In order to conduct the research and apply the research result for design optimization, the water-lubricated bearing test device was designed and built based on seawater desalination pump. The journal orbit and circumferential pressure of journal bearing were analyzed. In the basis of dry-rotor test, bearing-rotor system experimental investigation was carried out under the startup process and steady revolution speed.

\section{Introduction of Test Device}

2.1. Desalination High Pressure Multistage Pump. The seawater desalination high pressure pump is the crucial equipment in the reverse osmosis seawater desalination project; as Figure 1 shows, it is the typical multistage pump structure with two ends of water-lubricated journal bearing. In the pump operation process, the rotor system would bear the unbalancing force and unsteady fluid exciting force, of which the transient responses are very closely related. The transient dynamic characteristics would affect the eccentricity ratio, carrying capacity, damping, and stiffness coefficient and also have huge influence on the stability and reliability of the pump and the project.

2.2. The Overall Design of the Test Device. Based on structure of the seawater desalination high pressure pump, taking into account the safety and operability of loading and testing system, a test device was designed and built.

From Figure 2, we can see that the mechanical structure of the test device is mainly composed of the cylinder, journal bearing in driving and nondriving end, four discs, bracket, and pedestal. The shaft is supported by the journal bearings, which are mounted in the bearing base, and is driven by the frequency conversion motor through coupling. At the driving end bearing, the cartridge mechanical seal formed a little cavity with shaft and journal bearing. Outside the cavity, there is a mounting hole of pressure sensor and water inlet and outlet. In the nondriving end bearing, the end cap formed a large cavity with the shaft and journal bearing, of which outside there is a mounting hole for pressure sensor and water inlet and outlet. Both ends of journal bearing are connected to the cylinder through the flange. The assembly of the cylinder and the two ends of the journal bearing is fixed by the bracket on the pedestal. In the bottom of the cylinder there is a drain pipe joint. This design of the test device takes into account the simplification of the load system; four discs were mounted in the shaft and we adjust the radial load through the disc to simulate the radial load in the seawater desalination multistage high pressure pump. The advantage of this loading system is that the radial load can be adjusted through changing the quantity, weight, and thickness of disc with the simple and convenient operation. In addition, this test device can also conduct the test in dry and wet rotor.

\subsection{Test Plan and Sensor Installation}

2.3.1. Test Bench and Bearing Parameter. The parameter of the test bearing is as follows: the diameter is $43 \mathrm{~mm}$, lengthdiameter ratio is $0.7,0.8$, and 1 , the radius is $0.05 \mathrm{~mm}, 0.1 \mathrm{~mm}$, and $0.15 \mathrm{~mm}$, water-supply pressure is $0.3 \mathrm{MPa}$, and the revolution speed is $2000 \mathrm{r} / \mathrm{min}, 2500 \mathrm{r} / \mathrm{min}$, and $3000 \mathrm{r} / \mathrm{min}$. The test condition is the dry-rotor that means two-end water inlet and drain from the bottom of cylinder.

\subsubsection{Test Plan}

(1) Test Plan for Startup Process. The revolution speed is adjusted by the frequency conversion motor, the startup time was set to $16 \mathrm{~s}$, and we record the displacement and pressure distribution.

\section{(2) Test Plan for Steady Evolution Speed}

Test Plan 1. Revolution speed is $3000 \mathrm{r} / \mathrm{min}, L / D=1$, and radius clearance is $0.05 \mathrm{~mm}, 0.1 \mathrm{~mm}$, and $0.15 \mathrm{~mm}$. The tests in different radius clearance were conducted to analyze the influence on the system.

Test Plan 2. Revolution speed is $3000 \mathrm{r} / \mathrm{min}$, radius clearance is $0.05 \mathrm{~mm}$, and $L / D=0.7,0.8$, and 1 . Tests in different $L / D$ were conducted to analyze the influence on the system.

Test Plan 3. Radius clearance is $0.05 \mathrm{~mm}, L / D=1$, and revolution speed is $2000 \mathrm{r} / \mathrm{min}, 2500 \mathrm{r} / \mathrm{min}$, and $3000 \mathrm{r} / \mathrm{min}$. Tests in different revolution speed were conducted to analyze the influence on the system.

2.3.3. Sensor Installation. The research object of this test is the journal orbit and circumferential pressure distribution of the journal bearing. The rotation direction of the rotor is clockwise; as Figure 3 shows, 6 pressure sensors were mounted along the rotation direction, from number 1 to number 6 . As Figure 4 shows, a set of eddy current displacement 


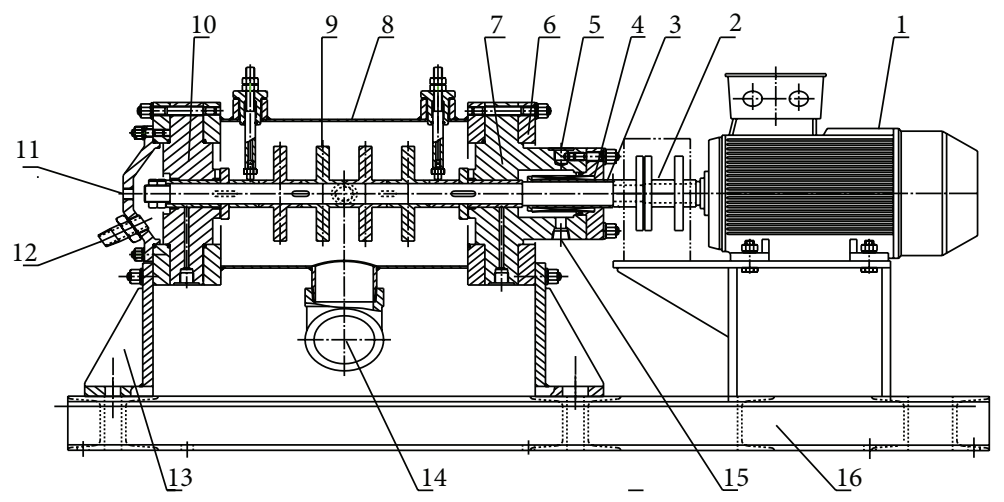
(1) Frequency conversion motor
(9) Disk
(2) Coupling
(3) Shaft
(10) Journal bearing in nondriving end
(4) Cartridge mechanical seals
(11) Measuring hole in nondriving end
(5) Driving end pressure measuring hole
(12) Inlet and outlet in nondriving end
(6) Flange
(7) Journal bearing in driving end
(8) Cylinder
(13) Bracket
(14) Large drain port
(15) Inlet and outlet in driving end
(16) Pedestal

Figure 2: Test device structure.

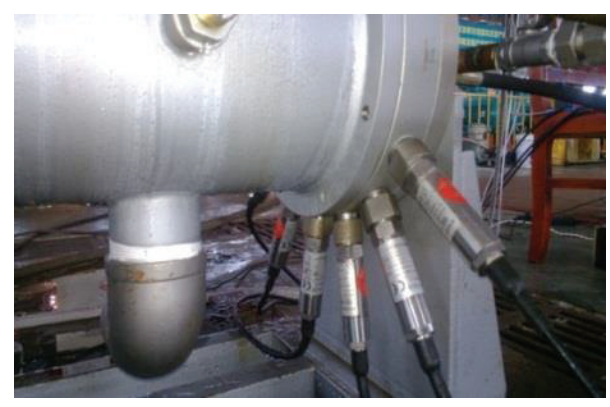

FIGURE 3: Pressure sensor installation.

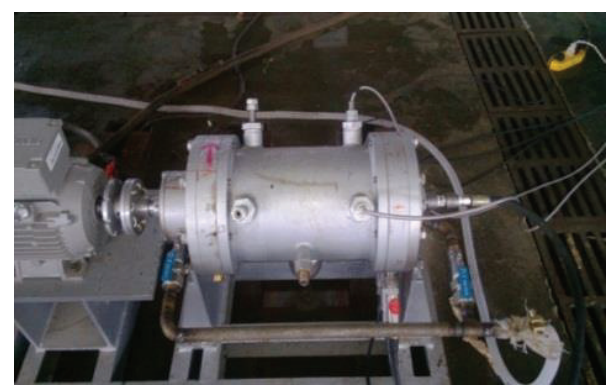

FIGURE 4: Eddy current displacement sensor installation.

sensors that are mutually perpendicular were mounted close to the journal bearing in the cylinder. The data recorded were analyzed by the data acquisition system as Figure 5 shows.

\section{The Analysis of Test in Startup Stage}

The axial displacement in $X$ and $Y$ directions and circumferential pressure distribution were recorded in the startup stage

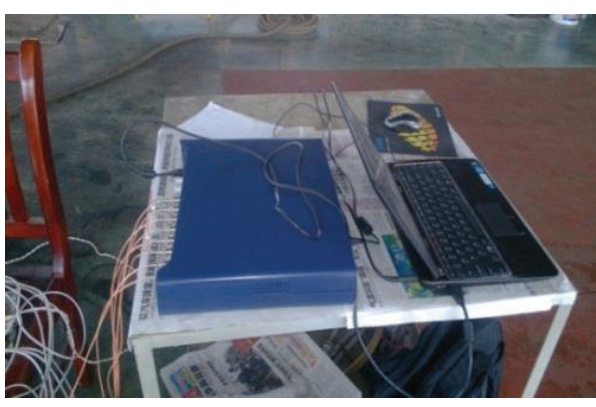

FIgURE 5: Data acquisition system.

of test device. NI PXI acquisition system records data of axial displacement and pressure in average 3 seconds.

\subsection{The Analysis of the Test in Startup Stage}

3.1.1. The Analysis of Journal Orbit in Startup Stage. After the data processing by the data acquisition system, three figures of journal orbit in different time are shown (Figures 6(a), 6(b), and $6(\mathrm{c}))$.

(i) In $0-4 \mathrm{~s}$ of the startup stage, due to the process the journal from static to rotational will be accompanied by the formation of dynamic pressure water film. The dry friction between the bearing bushing and journal transferred to boundary friction. Therefore, this kind of instability would cause the great volatility in journal orbit. With the increase of revolution speed, the journal is lifted and moved toward the rotation direction by the water film force, and the journal orbit gradually stabilized with small whirling amplitude.

(ii) In $4 \mathrm{~s}-8 \mathrm{~s}$ of the startup stage, Figure 6(b) shows the chaotic orbits and unstable whirling center. This is due 


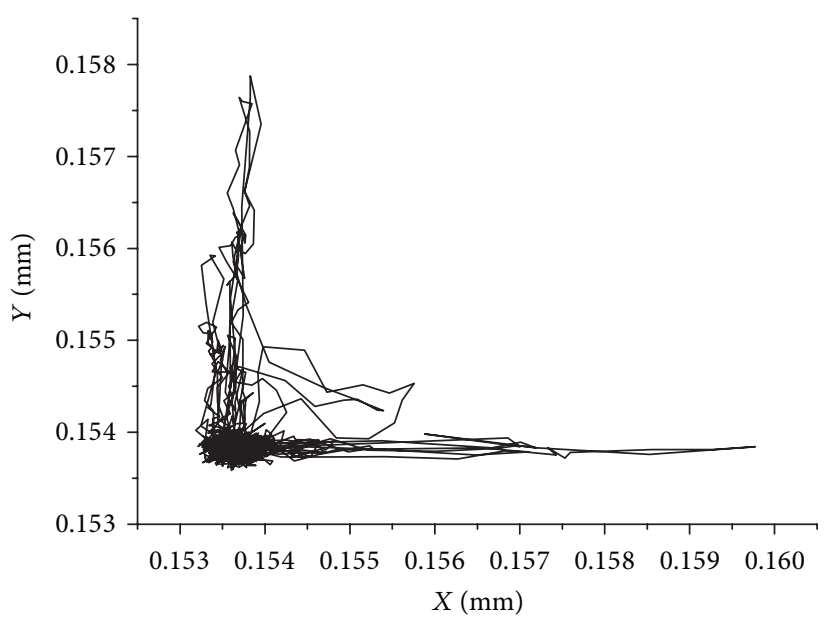

(a) The journal orbit in $0-4 \mathrm{~s}$

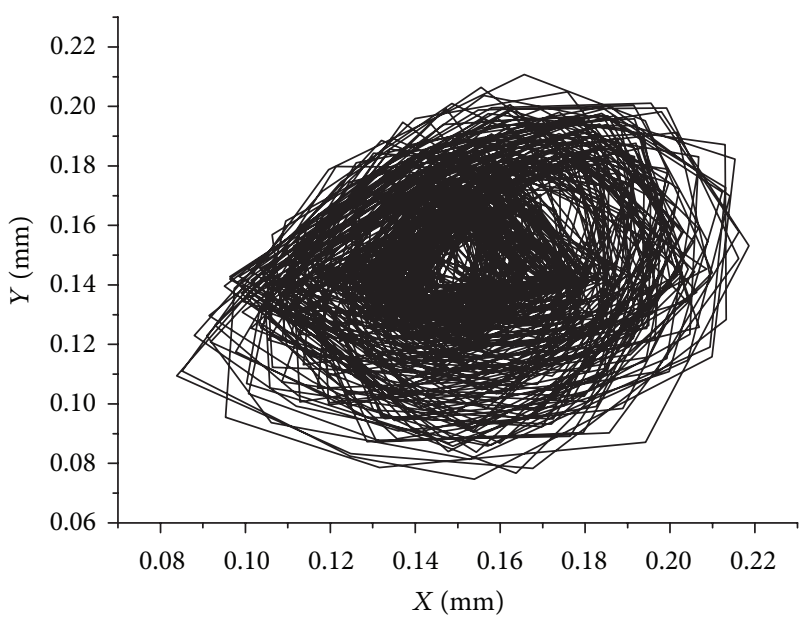

(b) The journal orbit in $4-10 \mathrm{~s}$

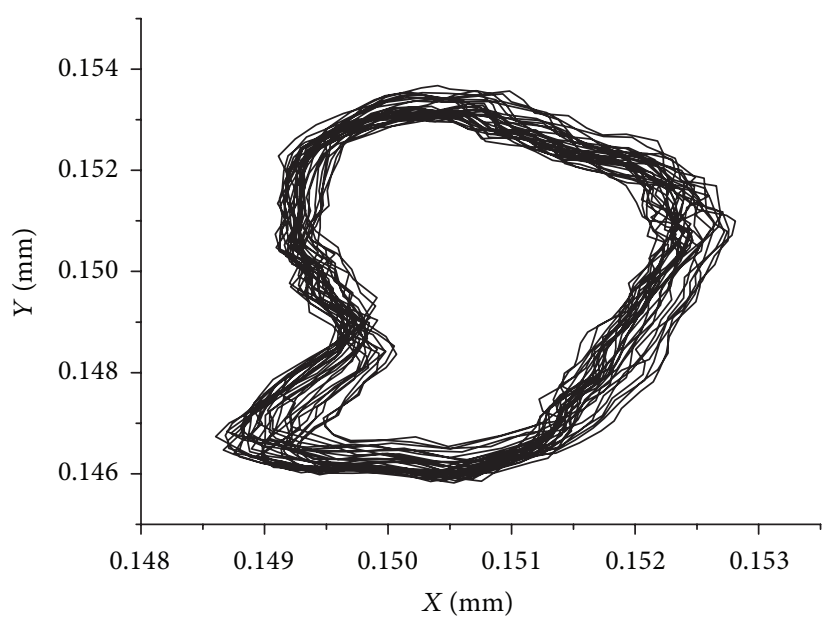

(c) The journal orbit in $10-16 \mathrm{~s}$

FIGURE 6: Journal orbit in startup stage.

to the increase in revolution speed; the hydrodynamic lubrication formed gradually, but the unstable lubrication condition results in the unstable water film force.

(iii) In 8 s-16 s of the startup stage, Figure 6(c) shows the journal orbit with stable whirling center, of which the shape is similar to oval; this is because the hydrodynamic lubrication has been basically formed and water film is stable.

3.1.2. Circumferential Pressure Distribution Analysis of Journal Bearing in Startup Stage. From Figure 7, we can see that, in $0-2 \mathrm{~s}$ of the startup stage, the rotor started and brought the water into the journal and bearing busing, but due to the small revolution speed, pressure is small and change is little. In 2-4 s, pressure begins to change, pressure in measure points number 1 and number 2 rises, and the rest drop, which is due to the unstable water film during the startup period. In $8 \mathrm{~s}$, dynamic pressure water film formed gradually and pressure increases with time. After $11 \mathrm{~s}$, although there is obvious periodic vibration, pressure is stable in each

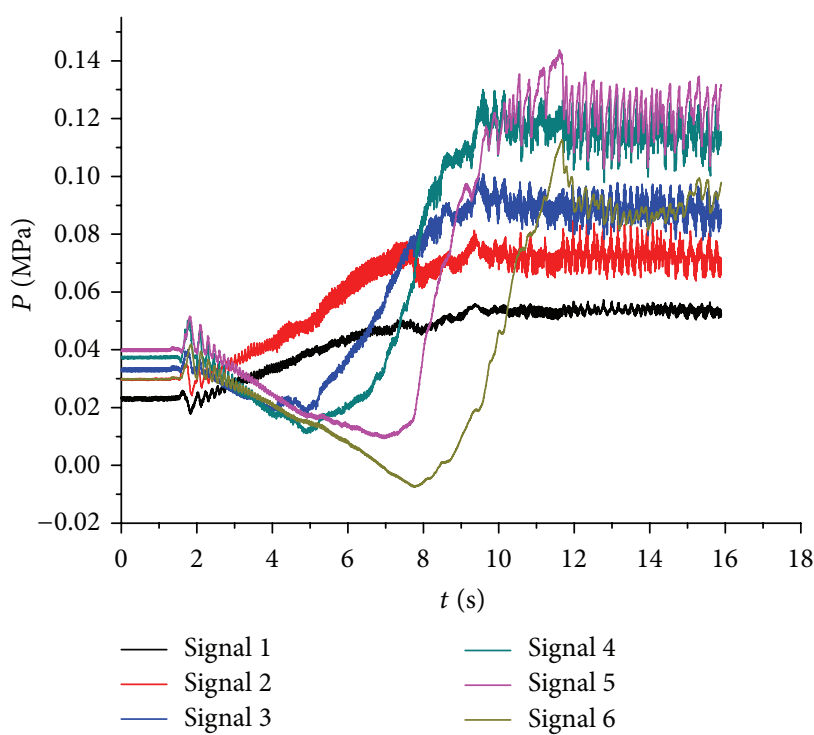

FIGURE 7: The circumferential pressure distribution of the startup stage. 


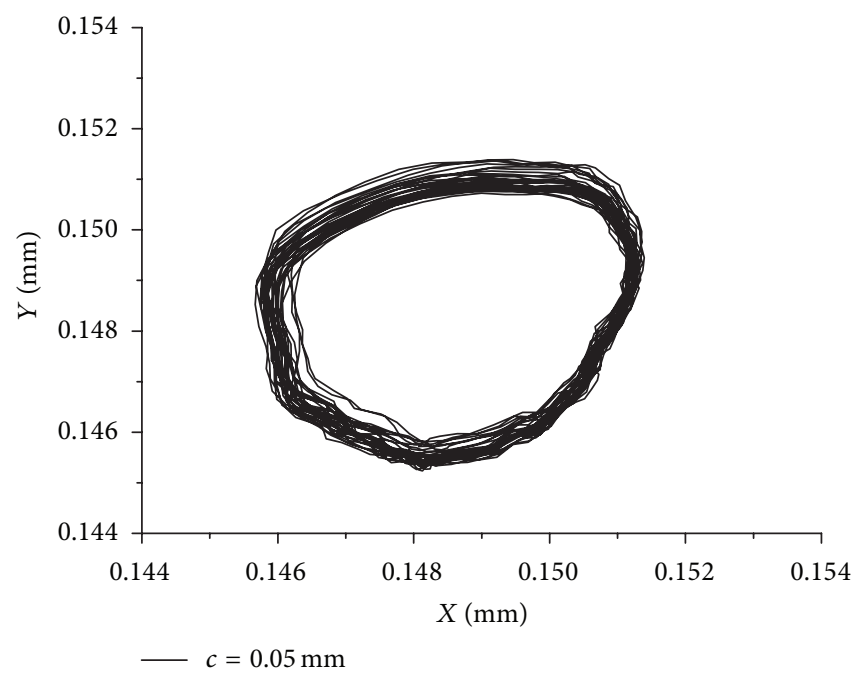

(a) $c=0.05 \mathrm{~mm}$

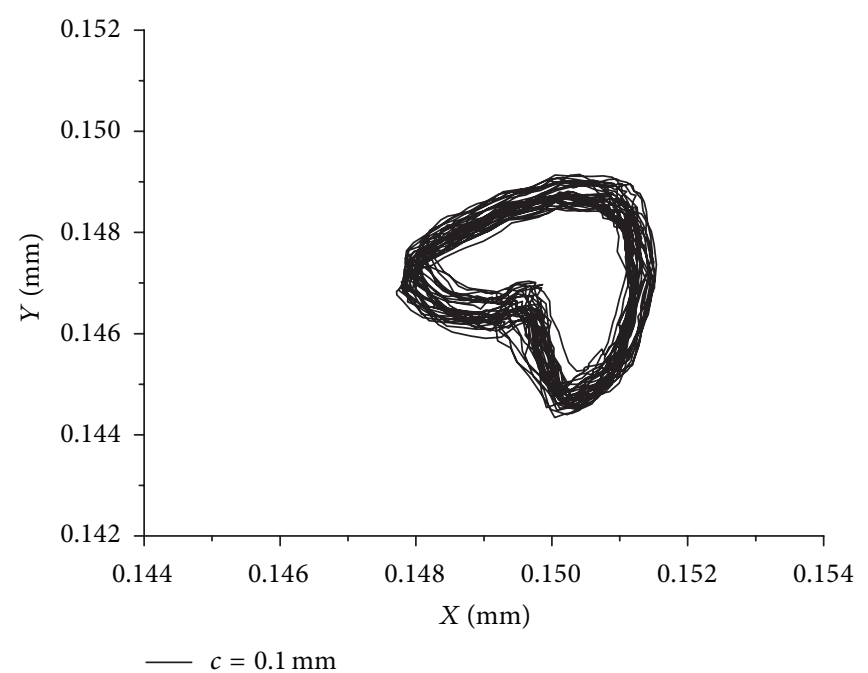

(b) $c=0.1 \mathrm{~mm}$

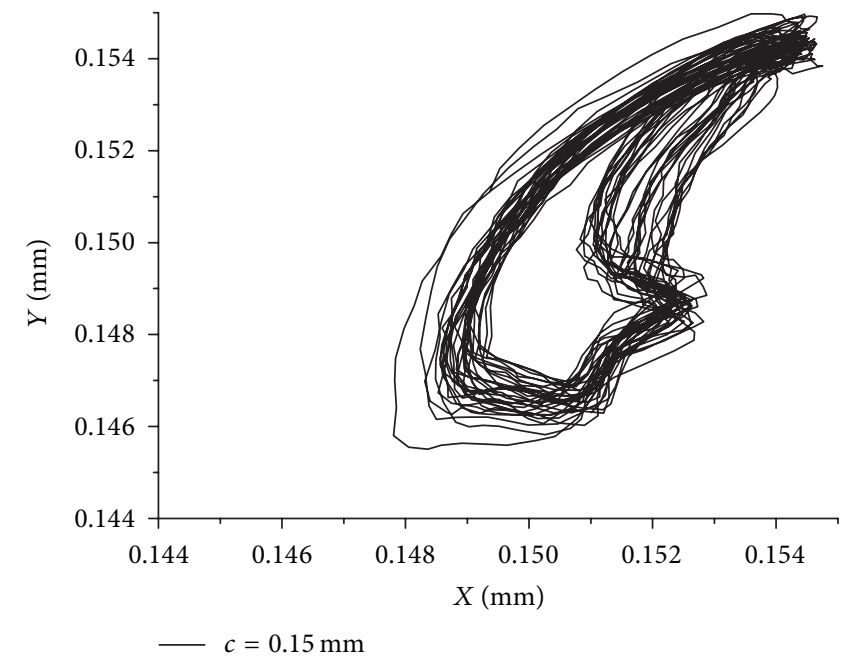

(c) $c=0.15 \mathrm{~mm}$

FIGURE 8: The journal orbit in different radius clearance.

pressure measure point. According to the journal orbit and the arrangement of pressure sensor, pressure measure points number 1 to number 5 are almost located in convergence zone of water-lubricated bearing, and the pressure gradually increases along the axial direction and reaches the maximum value in measure point number 4 , which is consistent with the measure result. The pressure in measure point number 6 is located in the divergent gap, which is also consistent with the measure result.

\section{Test Result Analysis under Stable Revolution Speed}

\subsection{The Influence of Radius Clearance on Bearing-Rotor System}

4.1.1. The Analysis of Journal Orbit in Different Radius Clearance. When $L / D=1$ and revolution speed is $3000 \mathrm{r} / \mathrm{min}$, the journal orbits of the radius clearance $c=0.15 \mathrm{~mm}, 0.1 \mathrm{~mm}$, and $0.05 \mathrm{~mm}$ were obtained. We can see from Figure 8 that the clearance affects the journal orbit obviously. When $c$ $=0.05 \mathrm{~mm}$, the regular whirling shape and stable whirling center which are caused by the rotor eccentricity indicate that the bearing-rotor system is stable. When $c=0.01 \mathrm{~mm}$, although the whirling center is stable, the journal orbit is irregular. The journal orbit indicates that the bearing-rotor system is unstable and the water film vibration failure may occur. When $c=0.15 \mathrm{~mm}$, the journal orbit vibrates obviously and the irregular journal orbit caused the large span in $X$ and $Y$ directions. The bearing-rotor system is not stable.

4.1.2. The Analysis of Circumferential Pressure Distribution in Different Radius Clearance. From Figure 9, we can see that when $c=0.05 \mathrm{~mm}$, pressure vibration in each measure point has obvious periodicity and is stable. The pressure amplitude and the pressure vibration are very consistent with the theoretical analysis, especially in the wedge convergent 


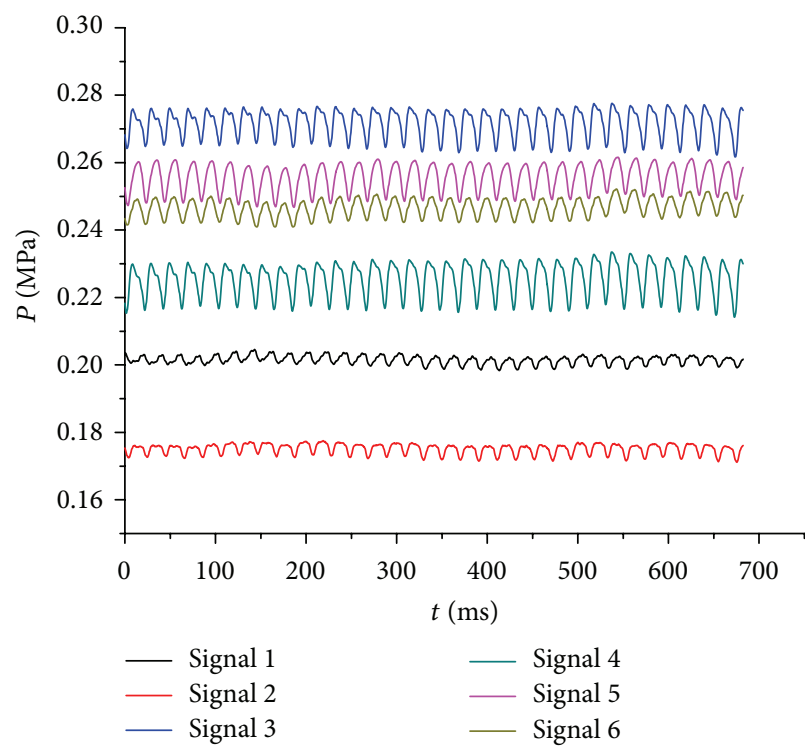

(a) $c=0.05 \mathrm{~mm}$

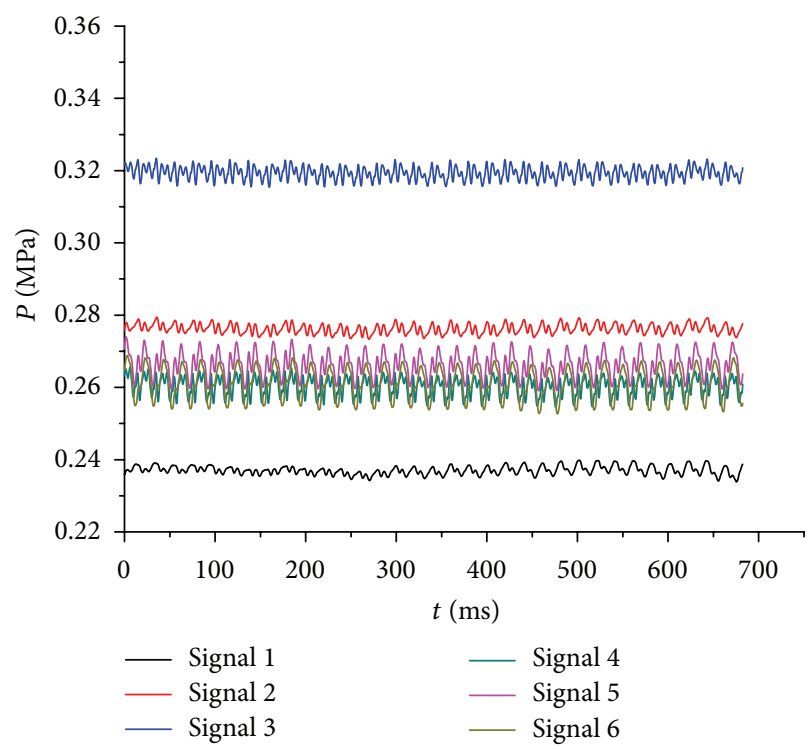

(b) $c=0.1 \mathrm{~mm}$

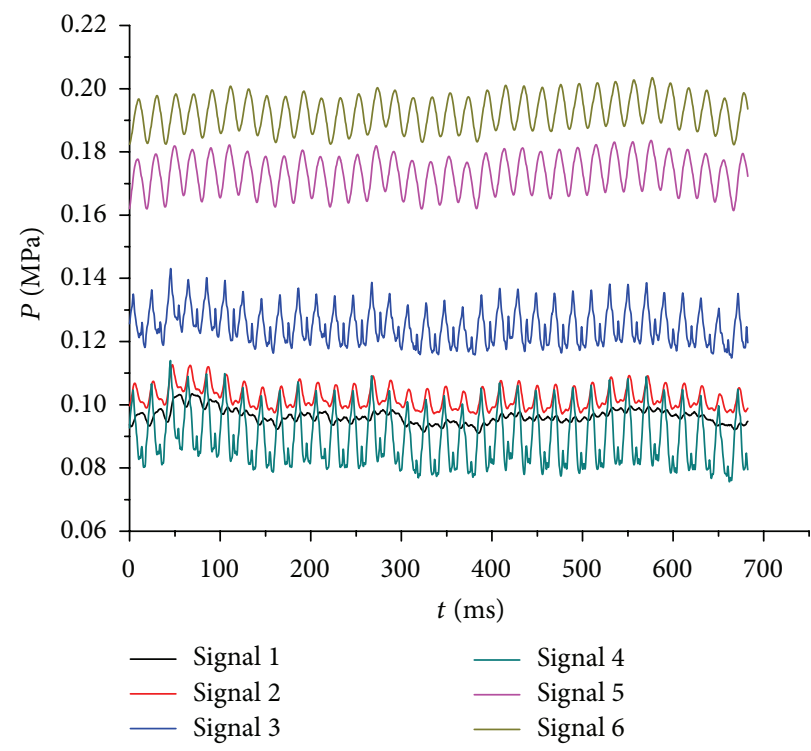

(c) $c=0.15 \mathrm{~mm}$

FIGURE 9: Circumferential pressure distribution in different radius clearance.

area, which indicate that the bearing-rotor system is very stable. When $c=0.1 \mathrm{~mm}$, pressure vibration in each measure point is small but the vibration period changes a lot as before. Besides measure points number 3 and number 6 , the pressure peak values of the rest are concentrated with no obvious pressure gradient, and combined with the journal orbit we can see that the bearing-rotor system began to be unstable. When $c=0.15 \mathrm{~mm}$, the vibration periodicity improved but the vibration amplitude is large and vibration shape is irregular; the peak value especially is in measure point number 6, which has large difference compared with theoretical analysis. Combined with the journal orbit, the bearing-rotor system is very unstable.

\subsection{The Influence of the Aspect Ratio on the Bearing-Rotor System}

4.2.1. The Analysis of Journal Orbit in Different Aspect Ratio. When $c=0.05 \mathrm{~mm}$, revolution speed is $3000 \mathrm{r} / \mathrm{min}$, and the journal orbits of the aspect ratio $L / D=0.7,0.8$, and 1 were obtained, from Figure 10, we can see that the $L / D$ has obvious influence in journal orbit. When $L / D=0.7$, the whirling center is unstable, and the journal orbit is irregular, the orbit overlapping occurred. When $L / D=0.8$, the journal orbit began to vibrate, and the orbit overlapping disappeared, the whirling center offsets toward the negative $X$ and $Y$ directions. The whirling shape change is obvious as before, the 


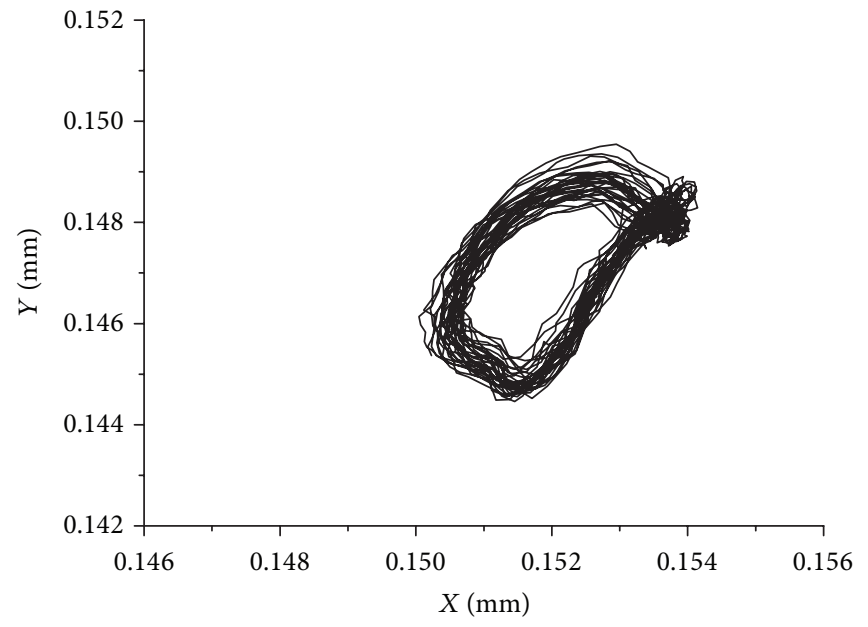

$-L / D=0.7$

(a) $L / D=0.7$

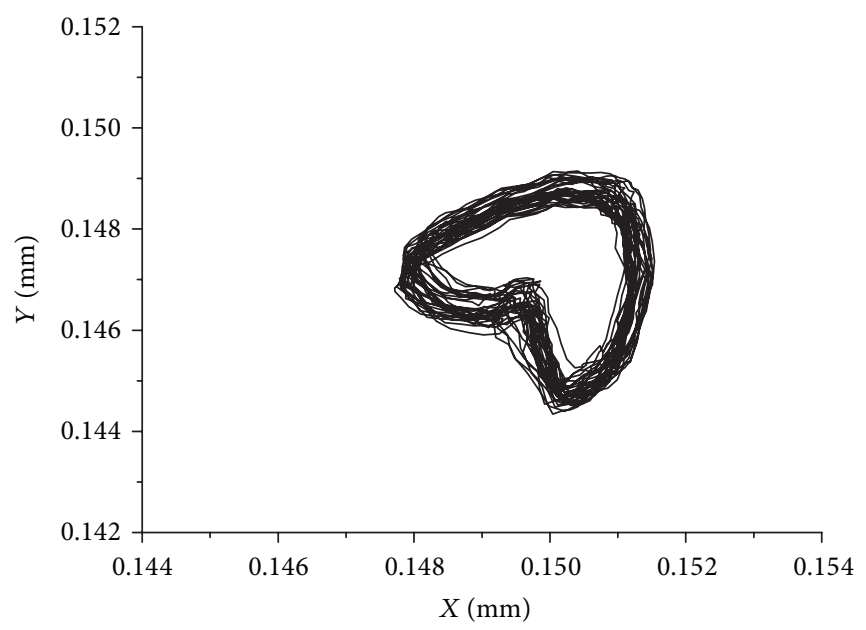

$L / D=0.8$

(b) $L / D=0.8$

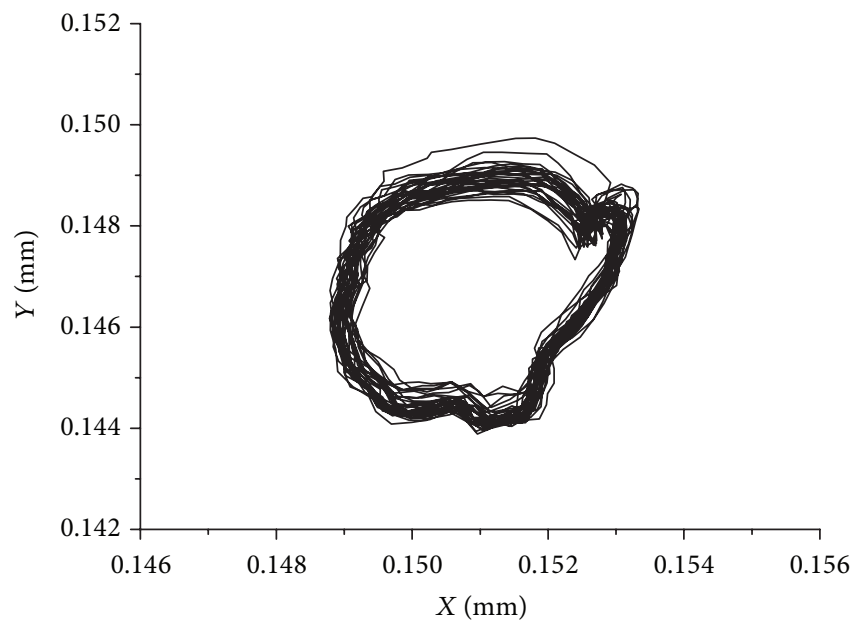

$-L / D=1$

(c) $L / D=1$

FIGURE 10: The journal orbit in different aspect ratio. 


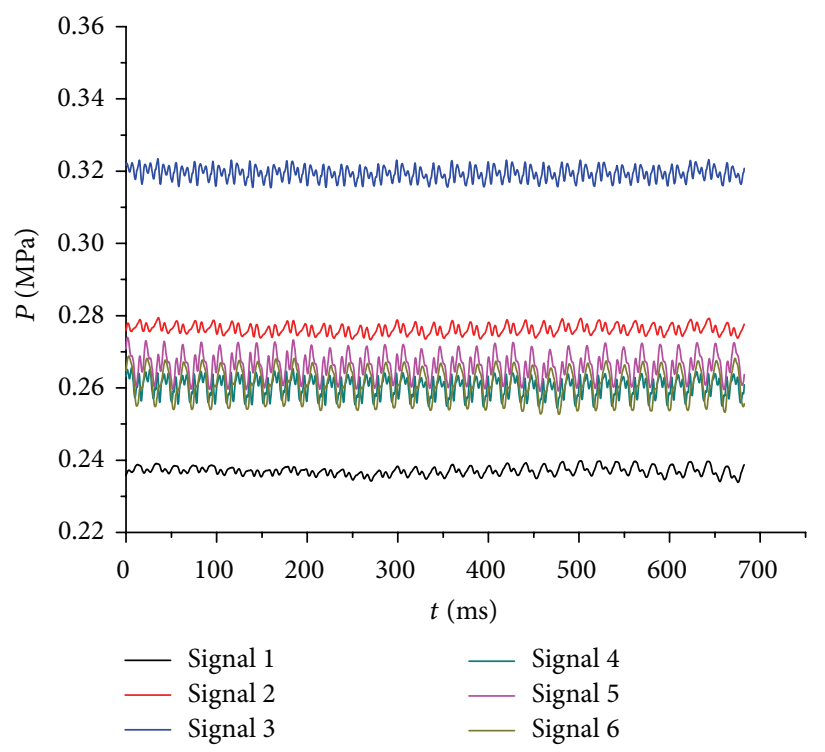

(a) $L / D=0.7$

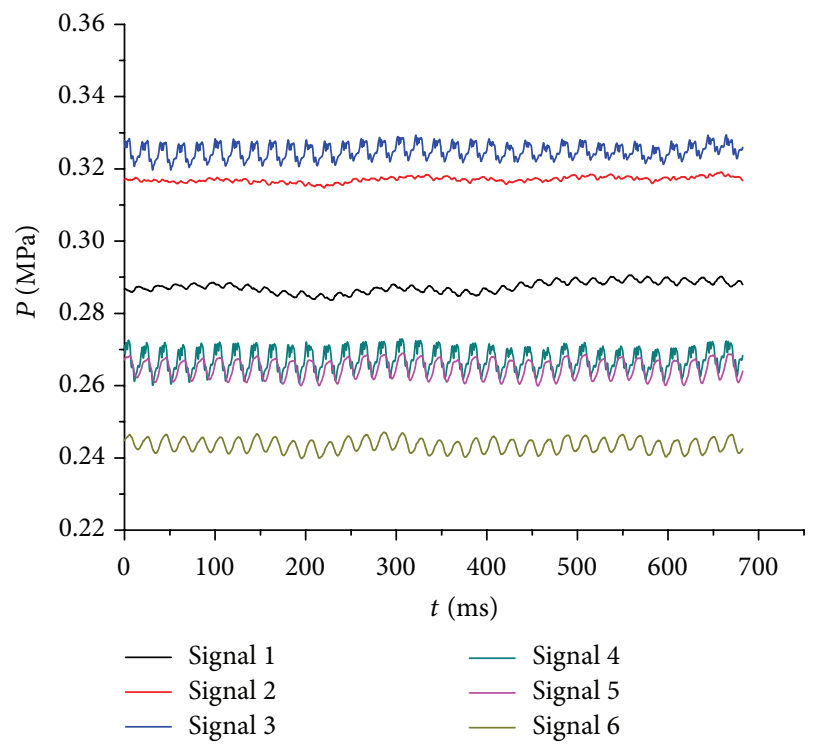

(b) $L / D=0.8$

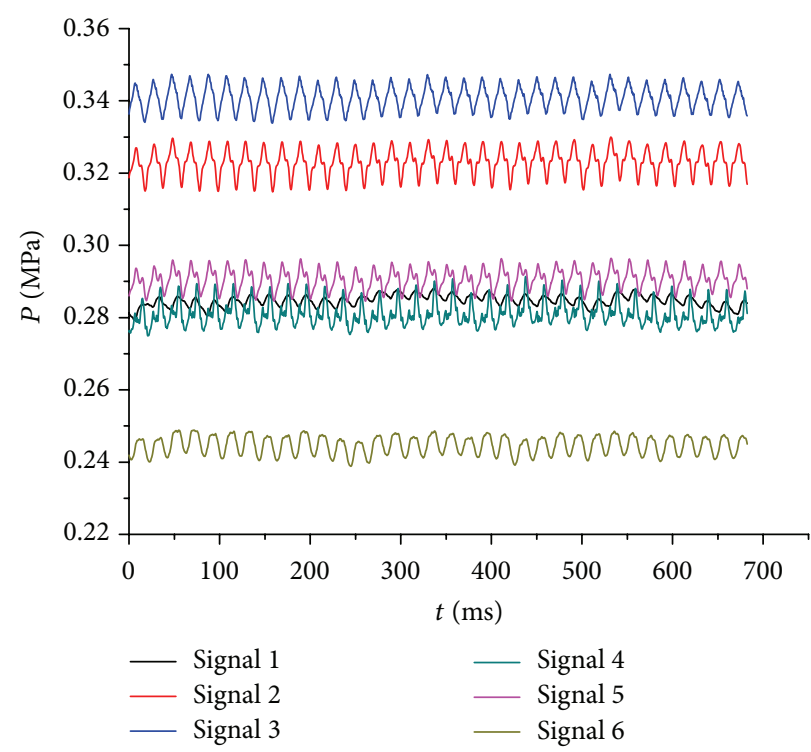

(c) $L / D=1$

FIGURE 11: Circumferential pressure distribution in different aspect ratio.

"inner eight" shape may be caused by the rotor misalignment, and the bearing-rotor system is still not stable. When $L / D=$ 1 , the stable whirling center and stable journal orbit appear. This indicates that the bearing-rotor system began to be stable.

4.2.2. The Analysis of Circumferential Pressure Distribution in Different Aspect Ratio. From Figure 11, when $L / D=$ 0.7 , vibration occurred in each pressure measure point, and the vibration periodicity is short besides measure points number 3 and number 6 , the peak values of the rest are concentrated with no obvious pressure gradient. Combined with the journal orbit, the bearing-rotor is not stable. When $L / D=0.8$, the pressure vibration periodicity is not obvious especially in measure points number 1 and number 2 , which indicates that the bearing-rotor system is not stable. When $L / D=1$, the pressure vibration periodicity improved and there is obvious pressure gradient in each pressure measure point, and the pressure amplitude is consistent with the theoretical analysis, this indicates that the bearing-rotor system began to be stable.

\subsection{The Influence of the Revolution Speed on the Bearing-Rotor System}

4.3.1. The Analysis of Journal Orbit in Different Revolution Speed. From Figure 12 we can see that the revolution speed has little influence in journal orbit, but only in the whirling amplitude. When $n=2000 \mathrm{r} / \mathrm{min}$, the slight journal orbit oscillation occurred; when $n=2500 \mathrm{r} / \mathrm{min}$, the journal 


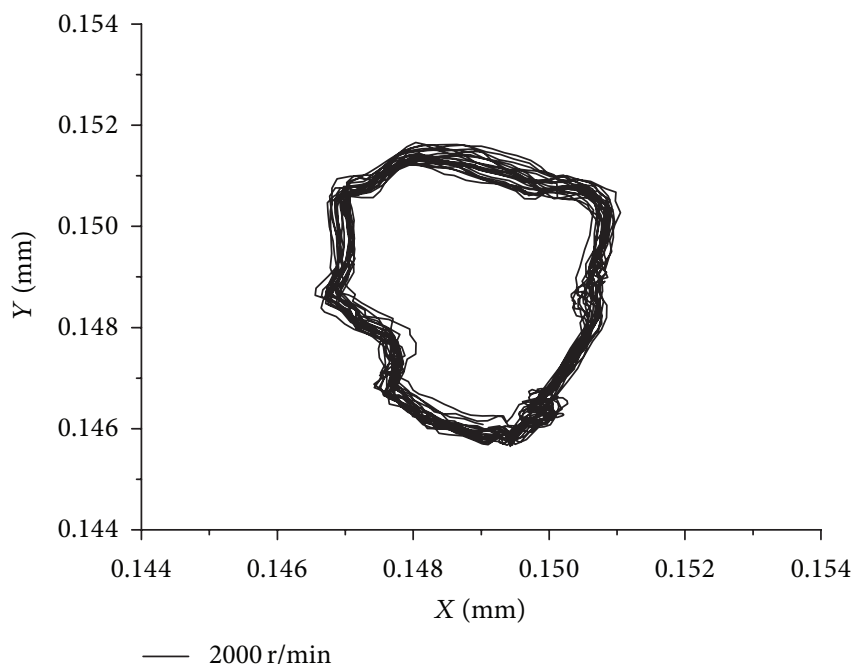

(a) $n=2000 \mathrm{r} / \mathrm{min}$

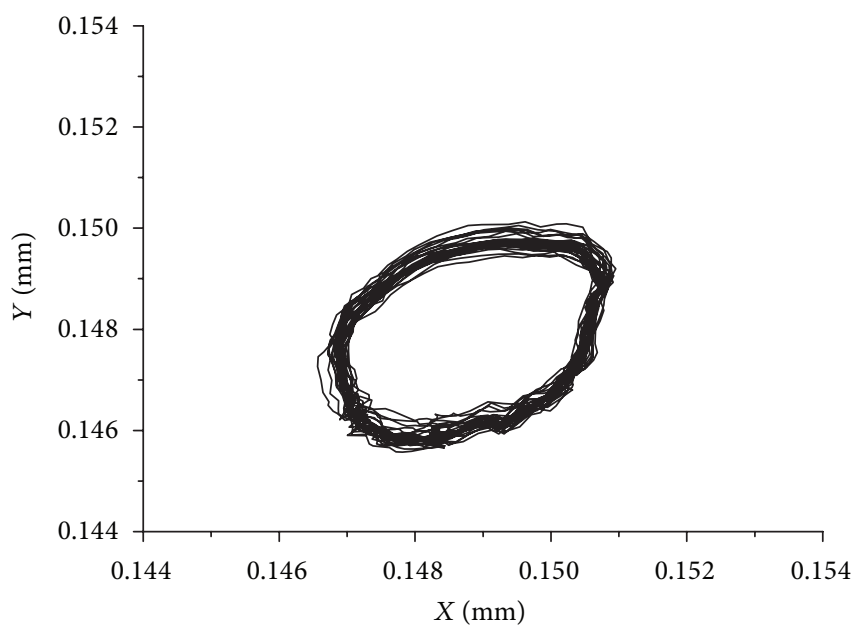

$2500 \mathrm{r} / \mathrm{min}$

(b) $n=2500 \mathrm{r} / \mathrm{min}$

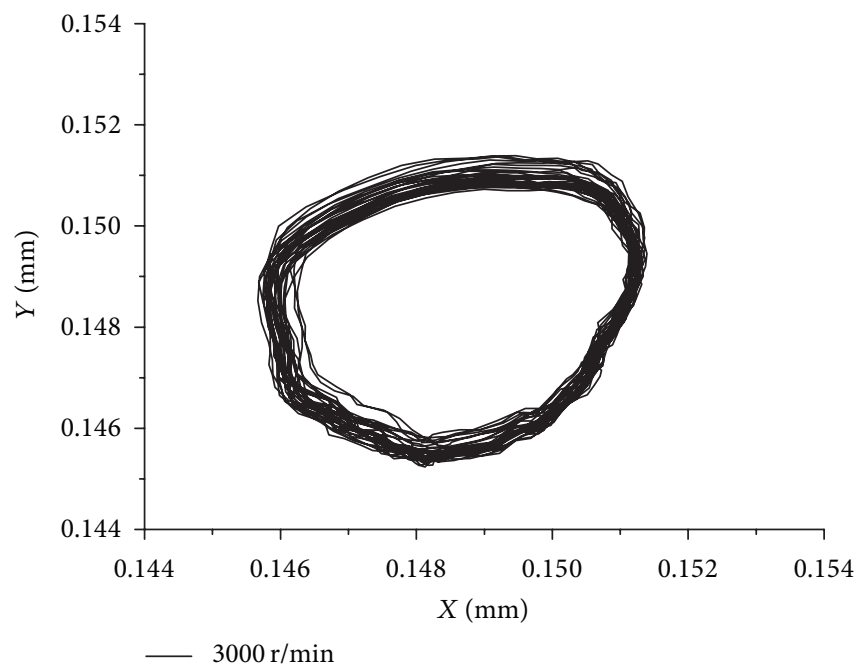

(c) $n=3000 \mathrm{r} / \mathrm{min}$

FIgURE 12: The journal orbit in different revolution speed. 


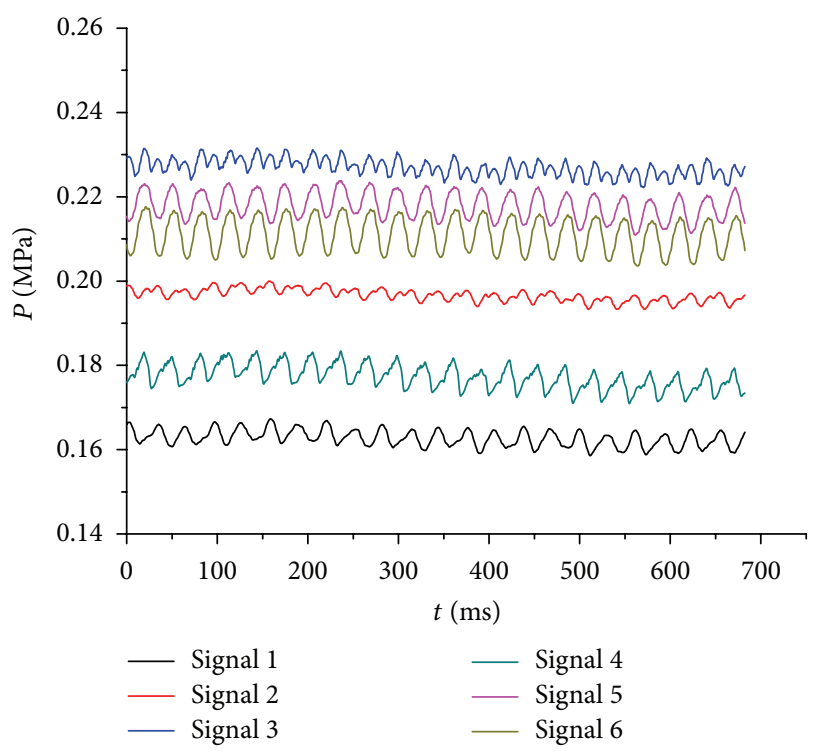

(a) $n=2000 \mathrm{r} / \mathrm{min}$

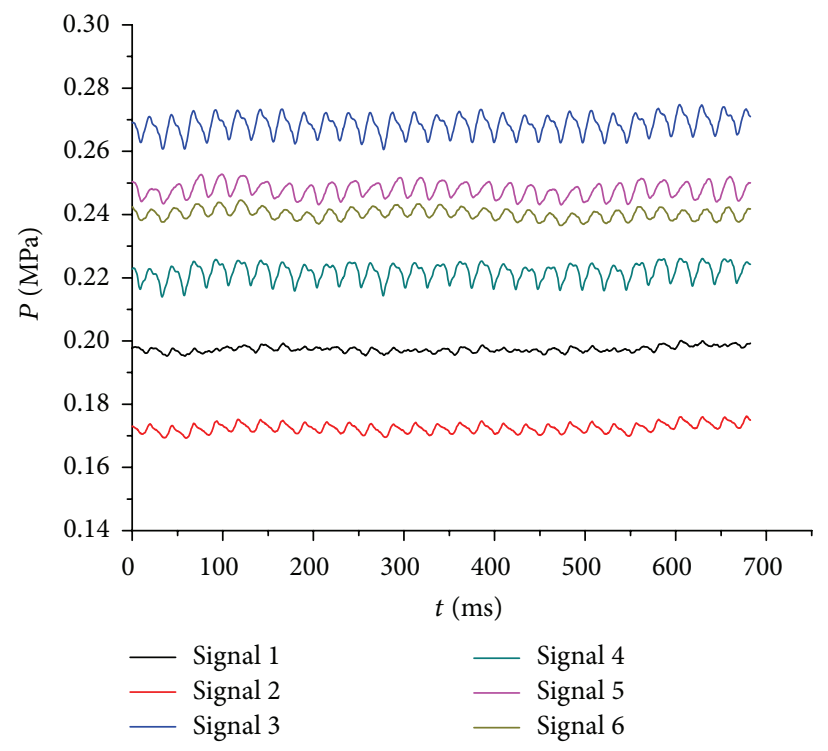

(b) $n=2500 \mathrm{r} / \mathrm{min}$

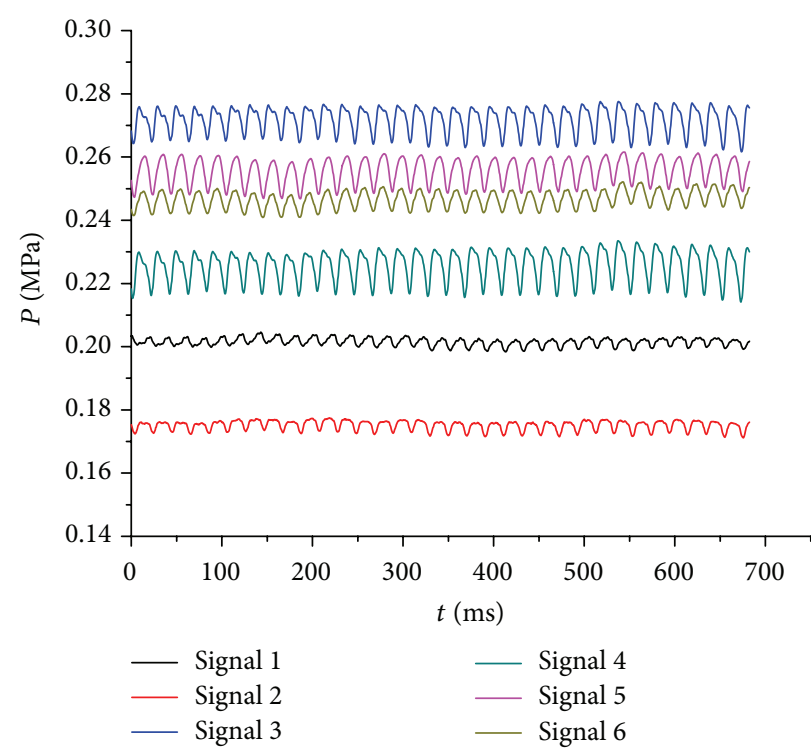

(c) $n=3000 \mathrm{r} / \mathrm{min}$

FIGURE 13: Circumferential pressure distribution in different revolution speed.

orbit began to be eliminated but the whirling amplitude also reduced; when $n=3000 \mathrm{r} / \mathrm{min}$, the journal orbit tends to be the oval and the whirling amplitude also increases. The above figures of journal orbit show that increasing the revolution speed can improve the stability of the bearing-rotor system.

4.3.2. The Analysis of Circumferential Pressure Distribution in Different Revolution Speed. From Figure 13, we can see that the main influence of revolution speed reflects in pressure vibration periodicity and stability. In $n=2000 \mathrm{r} / \mathrm{min}$ and $2500 \mathrm{r} / \mathrm{min}$, the pressure vibration and periodicity both are not stable. While in $n=3000 \mathrm{r} / \mathrm{min}$, we can see the very stable vibration periodicity which is consistent with the journal orbit, so this indicates that the bearing-rotor system is stable in $n=300 \mathrm{r} / \mathrm{min}$.

\section{Conclusion}

(1) The water-lubricated bearing test device was designed and built based on the prototype of high pressure pump with 4stage rotors. The journal orbit and circumferential pressure of journal bearing were analyzed. In the basis of dry-rotor, bearing-rotor system experimental investigation was carried out under the startup process and steady revolution speed. The running state of the test device is close to the actual pump operating condition, so the test result can provide some reference for the optimization design of the water-lubricated bearing of desalination high pressure pump.

(2) During the startup stage, the journal whirled with little amplitude in low revolution speed, and as the revolution speed increased, the journal began to move irregularly. The 
hydrodynamic lubrication formed basically when close to the rated revolution speed; there are stable whirling center and amplitude of the journal orbit. The circumferential pressure distribution of journal bearing changed severely and kept consistent with the change of journal orbit; when the revolution speed reached the rated speed, the pressure distribution is stable

(3) The journal bearing parameters, such as the aspect ratio and radius clearance, have influence on the stability of the bearing-rotor system. Reducing the radius clearance can improve the system stability; when $c=0.05 \mathrm{~mm}$, the system tends to be stable in this test. The appropriate aspect ratio can also improve the stability; when $L / D=1$, the system tends to be stable in this test. Increasing the revolution speed can improve the system stability; when $n=3000 \mathrm{r} / \mathrm{min}$, the system tends to be stable in this test.

\section{Competing Interests}

The authors declare that they do not have any commercial or associative interests that represent competing interests in connection with the work.

\section{Acknowledgments}

The authors are thankful for the support of Key Project of National Natural Science Foundation of China under Grant no. 51276083, the National Science and Technology Support Program of China under Grant no. 2013BAB08B02, and project supported by the Jiangsu Provincial College of Science and Engineering.

\section{References}

[1] X. Wang, K. Kato, and K. Adachi, "Running-in effect on the load-carrying capacity of a water-lubricated SiC thrust bearing," Proceedings of the Institution of Mechanical Engineers J: Journal of Engineering Tribology, vol. 219, no. 2, pp. 117-124, 2005.

[2] B.-H. Rho and K.-W. Kim, "A study of the dynamic characteristics of synchronously controlled hydrodynamic journal bearings," Tribology International, vol. 35, no. 5, pp. 339-345, 2002.

[3] R. Brancati, E. Rocca, and R. Russo, "Non-linear stability analysis of a rigid rotor on tilting pad journal bearings," Tribology International, vol. 29, no. 7, pp. 571-578, 1996.

[4] Y. Lu, L. Yu, and H. Liu, "Nonlinear dynamic characteristics of hydrodynamic journal bearing-flexible rotor system," Chinese Journal of Mechanical Engineering, vol. 18, no. 1, pp. 58-63, 2005.

[5] L. Roy and S. K. Laha, "Steady state and dynamic characteristics of axial grooved journal bearings," Tribology International, vol. 42, no. 5, pp. 754-761, 2009.

[6] M. Chernets and. Ju, "Source," in Proceedings of the Institution of Mechanical Engineers, Part J:Journal of Engineering Tribology, v 229, pp. 216-226, 2015.

[7] M. Y. Temis and A. P. Lazarev, "Calculation of six-lobe and eight-lobe deformable thrust sliding bearings," Journal of Friction and Wear, vol. 33, no. 1, pp. 60-71, 2012.

[8] K. S. Akhverdiev, B. M. Flek, and K. A. Vaneev, "Calculation model of compressible conductive lubricant for thrust sliding bearings under a harmonically varying magnetic field," Journal of Machinery Manufacture and Reliability, vol. 44, no. 1, pp. 5763, 2015.

[9] V. K. Akhmetov, Y. V. Medvedev, and V. Y. Shkadov, "Effect of the inertia terms in sliding bearing calculation problems," Fluid Dynamics, vol. 49, no. 3, pp. 320-329, 2014.

[10] Z. Guo, T. Hirano, and R. G. Kirk, "Application of CFD analysis for rotating machinery-Part I: hydrodynamic, hydrostatic bearings and squeeze film damper," Journal of Engineering for Gas Turbines and Power, vol. 127, no. 2, pp. 445-451, 2005.

[11] K. P. Gertzos, P. G. Nikolakopoulos, and C. A. Papadopoulos, "CFD analysis of journal bearing hydrodynamic lubrication by Bingham lubricant," Tribology International, vol. 41, no. 12, pp. 1190-1204, 2008.

[12] V. Meruane and R. Pascual, "Identification of nonlinear dynamic coefficients in plain journal bearings," Tribology International, vol. 41, no. 8, pp. 743-754, 2008.

[13] H. Liu, H. Xu, P. J. Ellison, and Z. Jin, “Application of computational fluid dynamics and fluid-structure interaction method to the lubrication study of a rotor-bearing system," Tribology Letters, vol. 38, no. 3, pp. 325-336, 2010.

[14] P. G. Tucker and P. S. Keogh, "On the dynamic thermal state in a hydrodynamic bearing with a whirling journal using CFD techniques," Journal of Tribology, vol. 118, no. 2, pp. 356-363, 1996.

[15] Z.-R. Hao and C. W. Gu, "Numerical modeling for gaseous cavitation of oil film and non-equilibrium dissolution effects in thrust bearings," Tribology International, vol. 78, pp. 14-26, 2014.

[16] L. Liu, The Development of Test-Bed of Water-Lubricated Bearing, HuaZhong University of Science and Technology, Wuhan, China, 2011.

[17] Y. Zhang and J. Wag, "The exploitation and design of waterlubrication dynamic-seal bearing test-bed," Lubrication Engineering, vol. 1, pp. 63-64, 2004.

[18] G. Zhang and X. Yuan, "Experimental study of dynamic characteristics of hard disk drivespindles supported by hydrodynamic bearing," Tribology, vol. 26, no. 3, pp. 238-241.

[19] T. Dimond and R. D. Rockwell, "A new fluid bearing test rig for oil and water bearing," in Proceedings of the ASME Turbo Expo: Power for Land, Sea, and Air, vol. 5, pp. 1101-1110, Berlin, Germany, June 2008.

[20] U. Ozsarac and F. Findik, "The wear behaviour investigation of sliding bearings with a designed testing machine," Materials \& Design, vol. 28, no. 1, pp. 345-350, 2007. 


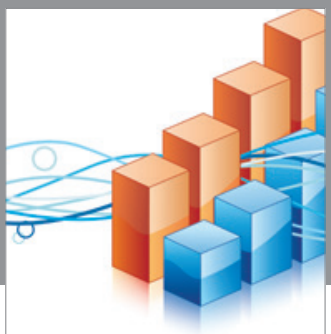

Advances in

Operations Research

vatem alat4

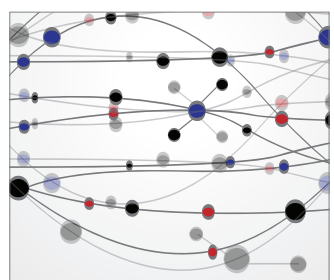

\section{The Scientific} World Journal
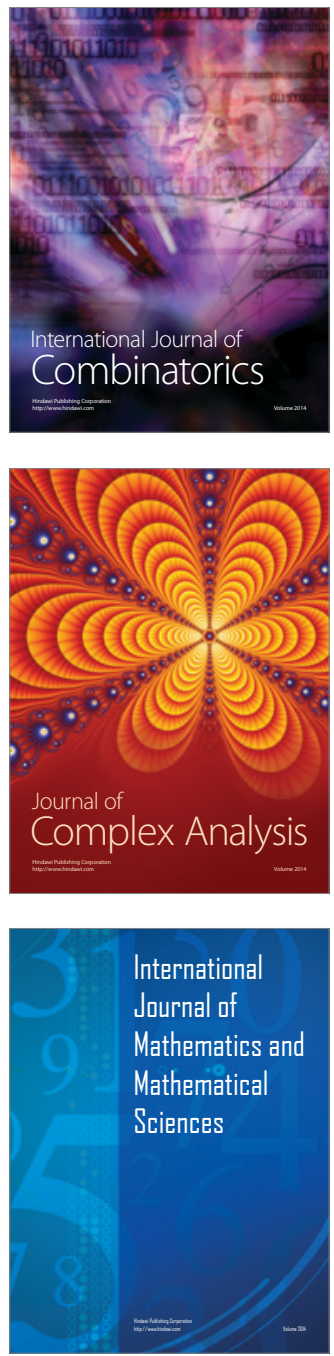
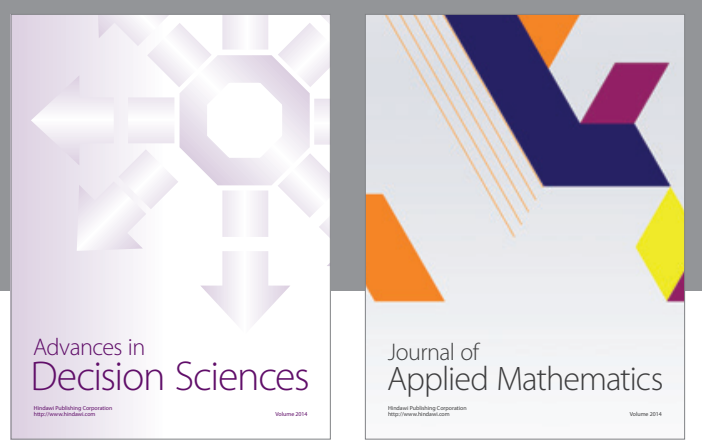

Algebra

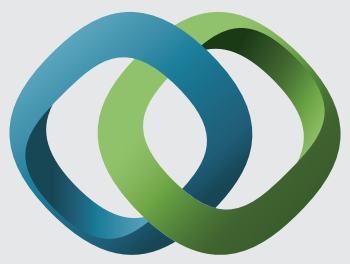

\section{Hindawi}

Submit your manuscripts at

http://www.hindawi.com
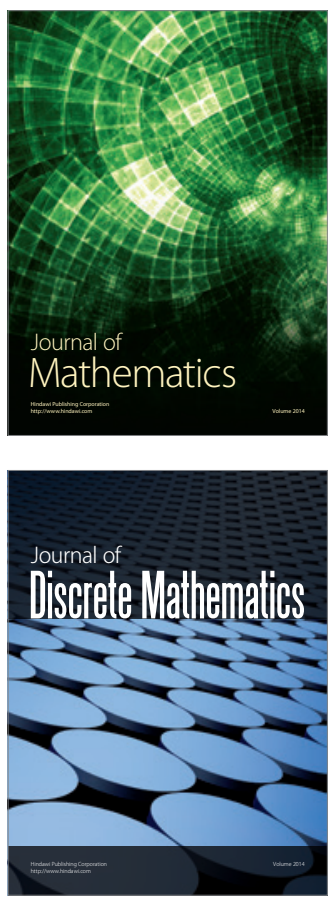

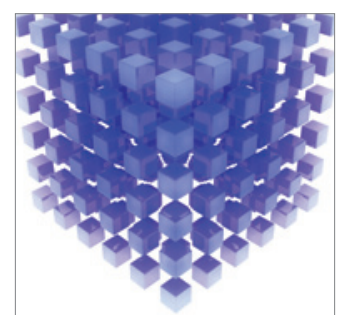

Mathematical Problems in Engineering
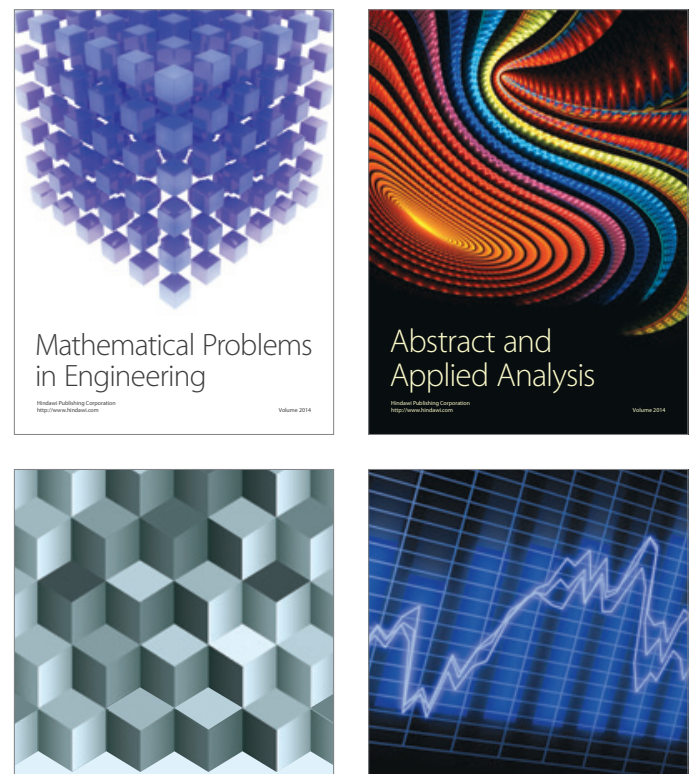

Journal of

Function Spaces

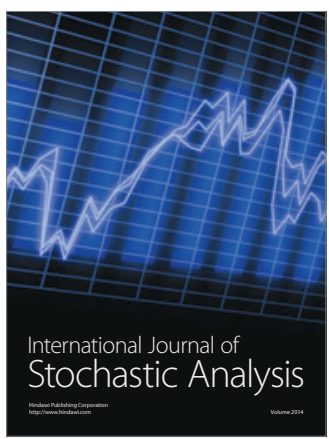

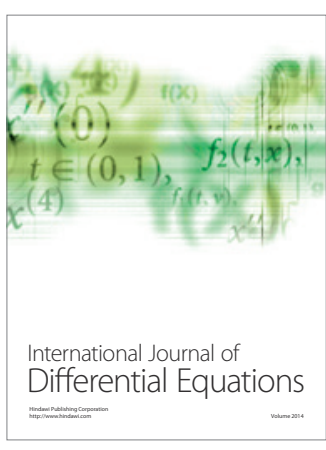
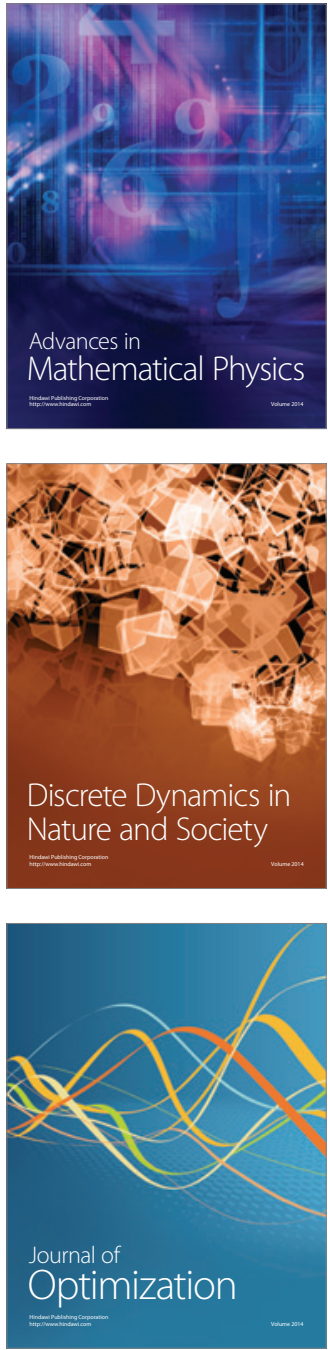